\title{
KARAKTERISTIK DAN KONSUMSI BAHAN BAKAR MINYAK SOLAR DENGAN MINYAK KEMIJEN PADA MOTOR DIESEL
}

\author{
Muhammad Nurtanto \\ Pendidikan Teknik Mesin, Fakultas Keguruan dan Ilmu Pendidikan-UNTIRTA \\ Email: mnurtanto23@untirta.ac.id
}

\begin{abstract}
ABSTRAK
Penelitian ini bertujuan untuk mengetahui karakteristik bahan bakar (minyak solar, minyak kemiri dan minyak wijen), karakteristik campuran bahan bakar, dan mengetahui besarnya konsumsi bahan bakar dengan variasi putaran mesin. Pengukuran dilakukan dengan menggunakan analyzer stargas 898. Data yang diperoleh dianalisis secara deskriptif dengan menggambarkan secara grafis dan fenomena terukur. Hasil pengujian diketahui bahwa: (1) karakteristik minyak kemiri, minyak wijen memenuhi karakteristik bahan bakar; (2) campuran bahan bakar minyak solar $80 \%$ dengan minyak kemiri 10\% dan minyak wijen 10\% menghasilkan karakteristik yang lebih baik; dan (3) konsumsi bahan bakar terhadap putaran mesin 1600 rpm, 2000 rpm, dan 2300 rpm yang lebih stabil pada campuran bahan bakar minyak solar 80\% dengan minyak kemiri 10\% dan minyak wijen 10\% masing-masing SFC yang diperoleh sebagai berikut 0.279882, 0.288938, dan 0.281213.
\end{abstract}

Kata Kuci: Minyak solar, minyak kemiri, minyak wijen, karakteristik bahan bakar, dan konsumsi bahan bakar.

\section{PENDAHULUAN}

Jumlah transportasi setiap tahunnya mengalami peningkatan. Kondisi ini berdampak pada konsumsi bahan bakar yang dibutuhkan, sedangkan asumsinya kebutuhan munyak yang digunakan lambat laun mengalami penurunan. Akibatnya harga bahan bakar mengalami peningkatan dan kualitas bahan bakar semakinmenurun. Permasalahan tersebut perlu dicarikan solusi baik berupa energy pengganti ataupun energy alternative.

Bahan bakar utama motor diesel adalah minyak solar. Solar merupakan hasil pengolahan dari minyak bumi, yang digunakan sebagai bahan bakar pengganti bensin. Energy alternative dengan karakteristik minyak yang layak adalah minyak kemiri dan minyak wijen melalui proses ekstrasi. Proses ekstrasi dapat dilakukan secara mekanis dan pelarutan (Ketaren, 1986). Biji kemiri merupakan salah satu hasil pertanian yang mengandung minyak (Siswani dan Kristianingrum, 2006). Kandungan minyak dalam biji kemiri tergolong tinggi, yaitu $55-66 \%$ dari berat bijinya (Arlena, Suharto, dan Susatlo, 2009). Minyak kemiri yang terkandung dalam bijinya juga memiliki banyak manfaat, antara lain bahan pembuat cat, pernis, sabun, obat, kosmetik, dan bahan bakar, ungkapan Arlena, Suharto, dan Jessica (2010). Minyak wijen sebagai energy alternative bio diesel. Rendemen minyak wijen berkisar antara 35-50\% Weiss (1971) dalam Sunanto (2002), artinya tergolong dengan kandungan minyak yang cupup tinggi.

Motor diesel adalah mesin pembangkit tenaga yang berfungsi untuk mengkonversikan kandungan energy panas atau kalor bahan bakar menjadi tenaga mekanik (Sukoco dan Zaenal Arifin, 2009:14). Sedangkan menurut Direktorat Pendidikan Menengah Kejuruan (2004:6) menyatakan bahwa motor diesel disebut dengan motor penyalaan kompresi (compression ignition engine) karena penyalaan bahan bakarnya diakibatkan oleh suhu kompresi udara dalam ruang bakar.Kebutuhan bahan bakar yang dibutuhkan memiliki karakteristik yang berbeda dengan jenis bahan bakar lainnya, sehingga diperlukan pengujian untuk memperoleh karkteristik yang sesuai.

Tujuan penelitian ini adalah (1) untuk mengetahui karakteristik minyak solar murni, minyak kemiri dan minyak wijen sebelum dilakukan pencampuran, (2) mengetahui karakteristik setelah dilakukan pencampuran dengan perbandingan tertentu, dan (3) pengaruh konsumsi bahan bakar dengan perbandingan campuran bahan bakar terhadap putaran mesin pada motor diesel. 


\section{BAHAN DAN CARA KERJA}

Bahan baku yang digunakan dalam penelitian ini adalah minyak solar murni, minyak kemiri murni dan minyak wijen murni yang diperoleh dari hasil ekstraksi. Sedangkan peralatan yang digunakan diantaranya buret, stop watch, dan motor diesel type 4JA1L - 4 cylinder inline. Pengujian karakteristik bahan bakar yang meliputi specific grafity, kinematic viscosity, flash point, dan pour point dilakukan di Laboratorium Teknologi Minyak Bumi Gas dan Batu Bara Universitas Gajah Mada.

Penelitian ini menggunakan metode eksperimen. Metode penelitian eksperimen dapat diartikan sebagai metode penelitian yang digunakan untuk mencari pengaruh perlakuan tertentu terhadap yang lain dalam kondisi yang terkendalikan (Sugiyono, 2013:107). Penelitian ini menggunakan desain ekperimen treatment by subject yaitu beberapa variasi perlakuan secara berturut-turut kepada kelompok subjek yang sama. Maksudnya untuk kelompok dikenakan perlakuan tertentu kemudian dilanjutkan pengukuran untuk mengetahui konsumsi bahan bakar spesifik (SFC) dan kadar emisi gas buang pada setiap variasi campuran bahan bakar yang berbeda.Perlakuan pada penelitian ini berupa minyak solar murni dengan minyak kemiri dan minyak wijen (sebagai subject) dengan campuran bahan bakar diantaranya: (1) minyak solar 90\% dengan minyak kemiri dan minyak wijen masing-masing 5\%; dan (2) minyak solar 80\% dengan minyak kemiri dan minyak wijen masing-masing $10 \%$ dan variasi putaran mesin yang diambil yaitu $1600 \mathrm{rpm}$, $2000 \mathrm{rpm}$, dan $2300 \mathrm{rpm}$.

\section{HASIL}

\section{Karakteristik Minyak Kemiri, Minyak Wijen dan Minyak Solar Murni}

Minyak kemiri dan minyak wijen dilakukan dari hasil ekstraksi yang akan digunakan sebagai campuran bahan bakar minyak solar.

a. Hasil penelitian dari karakteristik minyak kemiri

Kandungan yang diperoleh minyak kemiri berdasarkan hasil laboratorium sebagai berikut:

Tabel 1. Hasil Uji Laboratorium Minyak Kemiri Murni

\begin{tabular}{clccc}
\hline No. & \multicolumn{1}{c}{ Jenis Pemeriksaan } & Hasil & Satuan & Metode \\
\hline 1 & Specific Gravity at $60 / 60{ }^{0} \mathrm{~F}$ & 0,9227 & - & ASTM D 1298 \\
\hline 2 & Kinematic Viscosity $40{ }^{\circ} \mathrm{C}$ & 31,874 & $\mathrm{~mm}^{2} / \mathrm{s}$ & ASTM D 445 \\
\hline 3 & Flash Point PM.cc. & 241 & ${ }^{0} \mathrm{C}$ & ASTM D 93 \\
\hline 4 & Pour Point & 0 & ${ }^{0} \mathrm{C}$ & ASTM D 97 \\
\hline
\end{tabular}

b. Hasil penelitian dari karakteristik minyak wijen

Kandungan yang diperoleh minyak wijen berdasarkan hasil laboratorium, sebagai berikut:

Tabel 2. Hasil Uji Laboratorium Minyak Wijen Murni

\begin{tabular}{clccc}
\hline No. & \multicolumn{1}{c}{ Jenis Pemeriksaan } & Hasil & Satuan & Metode \\
\hline 1 & Specific Gravity at $60 / 60{ }^{0} \mathrm{~F}$ & 0,9157 & - & ASTM D 1298 \\
\hline 2 & Kinematic Viscosity $40{ }^{\circ} \mathrm{C}$ & 40,26 & $\mathrm{~mm}^{2} / \mathrm{s}$ & ASTM D 445 \\
\hline 3 & Flash Point PM.cc. & 255 & ${ }^{0} \mathrm{C}$ & ASTM D 93 \\
\hline 4 & Pour Point & 9 & ${ }^{0} \mathrm{C}$ & ASTM D 97 \\
\hline
\end{tabular}


c. Hasil penelitian dari karakteristik minyak solar

Kandungan yang diperoleh minyak solar murni berdasarkan hasil laboratorium, sebagai berikut:

Tabel 3. Hasil Uji Laboratorium Minyak Solar Murni

\begin{tabular}{clccc}
\hline No. & \multicolumn{1}{c}{ Jenis Pemeriksaan } & Hasil & Satuan & Metode \\
\hline 1 & Specific Gravity at $60 / 60{ }^{0} \mathrm{~F}$ & 0,852 & - & ASTM D 1298 \\
\hline 2 & Kinematic Viscosity $40{ }^{\circ} \mathrm{C}$ & 4,24 & $\mathrm{~mm}^{2} / \mathrm{s}$ & ASTM D 445 \\
\hline 3 & Flash Point PM.cc. & 75,0 & ${ }^{0} \mathrm{C}$ & ASTM D 93 \\
\hline 4 & Pour Point & 10 & ${ }^{0} \mathrm{C}$ & ASTM D 97 \\
\hline
\end{tabular}

Berdasarkan data di atas diperoleh bahwa specific gravity at $60 / 60{ }^{0} \mathrm{~F}$ bahwa minyak kemiri dan minyak wijen di atas minyak solar yaitu 0,9227 dan 0,9157 . Begitu juga untuk kinematic viscosity $40{ }^{0} \mathrm{C}$ hasil yang diperoleh lebih tinggi dibandingkan minyak solar yaitu $31,874 \mathrm{~mm}^{2} / \mathrm{s}$ dan $40,26 \mathrm{~mm}^{2} / \mathrm{s}$. untuk flash point PM.cc. nilai yang diperoleh minyak kemiri dan minyak wijen di atas minyak solar yaitu $241{ }^{\circ} \mathrm{C}$ dan 225 ${ }^{0} \mathrm{C}$. Sedangkan pour point minyak solar lebih tinggi yaitu $10{ }^{\circ} \mathrm{C}$.

\section{Karakteristik Campuran Minyak Kemiri, Minyak Wijen dan Minyak Solar}

a. Campuran minyak solar $90 \%$ dengan minyak kemiri 5\% dan minyak wijen 5\%

Pada volume $300 \mathrm{ml}$, yaitu minyak solar $270 \mathrm{ml}$, minyak kemiri dan minyak wijen masing-masing $15 \mathrm{ml}$ dicampur menjadi satu. Hal ini dilakukan untuk melihat karakteristik campuran dengan minyak solar murni. Kandungan yang diperoleh dari campuran tersebut berdasarkan hasil laboratorium sebagai berikut:

Tabel 4. Hasil Uji Laboratorium Campuran Bahan Bakar (Minyak solar 90\% dengan minyak kemiri 5\% dan minyak wijen 5\%)

\begin{tabular}{clccc}
\hline No. & \multicolumn{1}{c}{ Jenis Pemeriksaan } & Hasil & Satuan & Metode \\
\hline 1 & Specific Gravity at $60 / 60{ }^{0} \mathrm{~F}$ & 0,8617 & - & ASTM D 1298 \\
\hline 2 & Kinematic Viscosity $40{ }^{\circ} \mathrm{C}$ & 4,992 & $\mathrm{~mm}^{2} / \mathrm{s}$ & ASTM D 445 \\
\hline 3 & Flash Point PM.cc. & 79,0 & ${ }^{0} \mathrm{C}$ & ASTM D 93 \\
\hline 4 & Pour Point & 12 & ${ }^{0} \mathrm{C}$ & ASTM D 97 \\
\hline
\end{tabular}

b. Campuran minyak solar $80 \%$ dengan minyak kemiri $10 \%$ dan minyak wijen $10 \%$ Pada volume $300 \mathrm{ml}$, yaitu minyak solar $240 \mathrm{ml}$, minyak kemiri dan minyak wijen masing-masing $30 \mathrm{ml}$ dicampur menjadi satu. Hal ini dilakukan untuk melihat karakteristik campuran dengan minyak solar murni. Kandungan yang diperoleh dari campuran tersebut berdasarkan hasil laboratorium sebagai berikut:

Tabel 5. Hasil Uji Laboratorium Campuran Bahan Bakar (Minyak solar 80\% dengan minyak kemiri 10\% dan minyak wijen 10\%)

\begin{tabular}{clccc}
\hline No. & \multicolumn{1}{c}{ Jenis Pemeriksaan } & Hasil & Satuan & Metode \\
\hline 1 & Specific Gravity at $60 / 60{ }^{0} \mathrm{~F}$ & 0,8677 & - & ASTM D 1298 \\
\hline 2 & Kinematic Viscosity $40{ }^{\circ} \mathrm{C}$ & 6,354 & $\mathrm{~mm}^{2} / \mathrm{s}$ & ASTM D 445 \\
\hline 3 & Flash Point PM.cc. & 84,0 & ${ }^{0} \mathrm{C}$ & ASTM D 93 \\
\hline 4 & Pour Point & 6 & ${ }^{0} \mathrm{C}$ & ASTM D 97 \\
\hline
\end{tabular}




\section{Hasil Pengujian Konsumsi Bahan Bakar Spesifik (SFC) terhadap Putaran Mesin}

Konsumsi bahan bakar spesifik (SFC) diperoleh dari konsumsi bahan bakar $(m f)$ dibagi dengan daya $(\mathrm{P})$, yaitu dengan formula $\mathrm{SFC}=\frac{m f}{P}(\mathrm{~kg} / \mathrm{kW}$-jam $)$ dan $m f$ diperoleh dari formula $m f=$ $\frac{b}{t} \cdot \frac{3600}{1000} \cdot \rho_{b b}(\mathrm{~kg} / \mathrm{jam})$ dimana, $\mathrm{b}$ merupakan volume buret dalam pengujian sebesar $50 \mathrm{cc}, \mathrm{t}$ merupakan waktu yang diperlukan untuk pengosongan buret dalam detik (s), dan $\rho_{b b}$ sebesar 0,84 gr/cc. menurut Kurdi dan Arijanto, 2007: 56 nilai $m f$ juga dapat diperoleh dengan formula $m_{f}=v / t \times \rho_{b b} \times 3,6(\mathrm{~kg} / \mathrm{jam})$. Nilai P (daya) diperoleh dengan menggunakan formula $P=\frac{2 \pi \cdot n . T}{60000}$ $(\mathrm{kW})$ sedangkan $\mathrm{T}$ diperoleh dari formula $\mathrm{T}=\mathrm{m} . \mathrm{g} . \mathrm{I}(\mathrm{Nm})$ dimana $\mathrm{T}$ merupakan torsi mesin dalam $\mathrm{Nm}, \mathrm{g}$ merupakan percepatan gravitasi senilai $9,81 \mathrm{~m} / \mathrm{s}^{2}$, I merupakan panjang lengan dynamometer sebesar $0,358 \mathrm{~mm}$, merupakan massa/beban yang diukur dalam $\mathrm{kg}$, dan $\mathrm{n}$ merupakan putaran mesin yang diperlukan dalam rpm.

Pengujian Konsumsi Bahan Bakar dengan Campuran minyak solar 90\% dengan Minyak Kemiri 5\% dan Minyak Wijen 5\% terhadap Putaran Mesin.

Hasil pengujian untuk konsumsi bahan bakar spesifik (SFC) dengan variasi putaran mesin yaitu $1600 \mathrm{rpm}, 2000 \mathrm{rpm}$, dan $2500 \mathrm{rpm}$ sebagai berikut:

Tabel 6. Hasil Uji Laboratorium Konsumsi Bahan Bakar dengan Campuran Minyak Solar 90\% dengan Minyak Kemiri dan Minyak Wijen 5\% terhadap Putaran Mesin 1600 rpm, 2000 rpm, dan 2500 rpm.

\begin{tabular}{cccccccc}
\hline No & $\begin{array}{c}\mathbf{n} \\
(\mathbf{R p m})\end{array}$ & $\mathbf{m}(\mathbf{K g})$ & $\begin{array}{c}\mathbf{T} \\
(\mathbf{N m})\end{array}$ & $\mathbf{P}(\mathbf{k W})$ & $\begin{array}{c}\mathbf{t} \\
(\mathbf{d e t i k})\end{array}$ & $\begin{array}{c}\mathbf{m f} \\
(\mathbf{k g} / \mathbf{j a m})\end{array}$ & $\begin{array}{c}\mathbf{S F C} \\
(\mathbf{k g} / \mathbf{k W}- \\
\mathbf{j a m})\end{array}$ \\
\hline 1 & 1600 & 33 & 115,9 & 19,42627 & 32,8 & 4,609756 & 0,237295 \\
\hline 2 & 2000 & 33 & 115,9 & 24,28283 & 21,65 & 6,983834 & 0,287604 \\
\hline 3 & 2500 & 20 & 70,24 & 18,39609 & 27,9 & 5,419355 & 0,294593 \\
\hline
\end{tabular}

Pada campuran minyak solar 90\% dengan minyak kemiri dan minyak wijen masing-masing 5\%, SFC terendah pada putaran mesin $1600 \mathrm{rpm}$ yaitu sebesar 0,237295 kg/kW-jam. Semakin tinggi putaran mesin SFC yang dihasilkan semakin meningkat artinya bahan bakar yang dibutuhkan semakin boros.

Pengujian Konsumsi Bahan Bakar dengan Campuran minyak solar 80\% dengan Minyak Kemiri 10\% dan Minyak Wijen 10\% terhadap Putaran Mesin.

Hasil pengujian untuk konsumsi bahan bakar spesifik (SFC) dengan variasi putaran mesin yaitu $1600 \mathrm{rpm}, 2000 \mathrm{rpm}$, dan $2500 \mathrm{rpm}$ sebagai berikut:

Tabel 7. Hasil Uji Laboratorium Konsumsi Bahan Bakar dengan Campuran Minyak Solar 80\% dengan Minyak Kemiri dan Minyak Wijen 10\% terhadap Putaran Mesin 1600 rpm, 2000 rpm, dan $2500 \mathrm{rpm}$.

\begin{tabular}{cccccccc}
\hline No & $\begin{array}{c}\mathbf{n} \\
(\mathbf{R p m})\end{array}$ & $\mathbf{m}(\mathbf{K g})$ & $\begin{array}{c}\mathbf{T} \\
(\mathbf{N m})\end{array}$ & $\mathbf{P}(\mathbf{k W})$ & $\begin{array}{c}\mathbf{t} \\
(\mathbf{d e t i k})\end{array}$ & $\begin{array}{c}\boldsymbol{m f} \\
(\mathbf{k g} / \mathbf{j a m})\end{array}$ & $\begin{array}{c}\mathbf{S F C} \\
(\mathbf{k g} / \mathbf{k W}- \\
\mathbf{j a m})\end{array}$ \\
\hline 1 & 1600 & 33,25 & 116,77 & 19,57344 & 27,6 & 5,478261 & 0,279882 \\
\hline 2 & 2000 & 33 & 115,9 & 24,28283 & 21,55 & 7,016241 & 0,288938 \\
\hline 3 & 2500 & 27 & 94,823 & 24,83472 & 21,65 & 6,983834 & 0,281213 \\
\hline
\end{tabular}


Pada campuran minyak solar $80 \%$ dengan minyak kemiri dan minyak wijen masing-masing $10 \%$, SFC terendah pada putaran mesin $1600 \mathrm{rpm}$ yaitu sebesar 0,279882 kg/kW-jam. Semakin tinggi putaran mesin SFC yang dihasilkan semakin meningkat artinya bahan bakar yang dibutuhkan semakin boros.

\section{PEMBAHASAN}

\section{A. Karakteristik Bahan Bakar Minyak Solar, Minyak Kemiri dan Minyak Wijen}

Hasil uji laboratorium berdasarkan karakteristik bahan bakar dapat dijelaskan pada gambar jenis pemeriksaan di bawah ini.

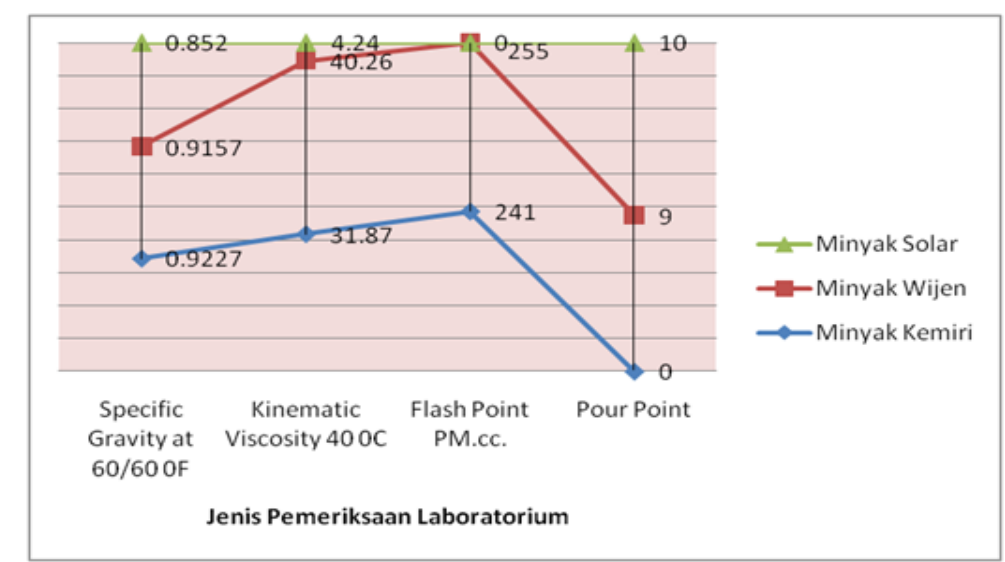

Gambar 1. Grafik Karakteristik Bahan Bakar Minyak Kemiri, Minyak Wijen dan Minyak Solar

Specific grafity (relative density) merupakan perbandingan massa sejumlah volume zat pada suhu tertentu terhadap massa air murni dengan volume yang sama pada suhu yang sama atau suhu yang berbeda. specific gravity dinyatakan dengan dua angja suhu, dimana angka ertama menunjukkan suhu zat dan angka kedua menunjukkan suhu air. SG pada 60/60 0F minyak solar antara $0.820-0.870$ artinya minyak solar tidak terkontaminasi. Apabila kurang dari angka tersebut maka minyak terkontaminasi oleh zat fraksi berat ataupun mengandung banyak senyawa naften dan aromat. Pada gambar grafik angka yang dihasilkan dari minyak kemiri, minyak wijen dan minyak solar melebihi 0.820 yaitu $0.9227,0.9157$ dan 0.852 . hasil tersebut menunjukkan bahwa specific grafity memenuhi kelayakan dari karakteristik bahan bakar.

Kinematic Viscosity (viskositas) adalah suatu ukuran dari dasar perlawanan zat cair untuk mengalir atau ukuran dari besarnya tahanan geser dalam dari suatu benda cair. Pada umumnya makin tinggi drajat API, makin kecil viscositasnya (Supraptono, 2004:27). Kinematic viscosity diperoleh dari perbandingan dynamic viscosity terhadap density. Satuan untuk dynamic viscosity adalah $\mathrm{Pa} \mathrm{s}$ atau Ns/m2 (=1 Pa s) atau $\mathrm{kg} / \mathrm{m} \mathrm{s}(=1 \mathrm{~Pa} \mathrm{~s})$ atau $\mathrm{g} / \mathrm{cm} \mathrm{s}(=0.1 \mathrm{~Pa} \mathrm{~s})$ atau dyne $\mathrm{s} / \mathrm{cm} 2(=0.1 \mathrm{~Pa} \mathrm{~s})$ atau poise, $\mathrm{P}(0.1 \mathrm{~Pa} \mathrm{~s})$ atau centiPoise, $\mathrm{cP}(=0.01 \mathrm{P})$. Hasil pengujian di atas diperoleh bahwa minyak kemiri dan minyak wijen memiliki viskositas yang lebih tinggi dibandingkan solar (4.24) yaitu (31.874) dan (40.26). Artinya bahan bakar tersebut memenuhi karakteristik sebagai bahan bakar.

Flash point PMcc (titik nyala) adalah suhu terendah dari bahan bakar munyak yang dapat menimbulkan nyala api dalam sekejap apabila pada permukaan bahan bakar minyak tersebut dipercikkan api (Supraptono, 2004:28). Flash point semakin rendah maka semakin mudah menguap dan terbakar. Flash point PMcc dari masing-masing bahan bakar sebagai berikut 
minyak kemiri (241), minyak wijen (255) dan minyak solar $(75,0)$. Hasil tersebut menunjukkan bahwa bahan bakar tidak mudah menguap dan membutuhkan waktu dalam pembakaran.

Pour point adalah suhu terendah dimana bahan bakar minyak masih dapat mengalir dengan sendirinya pada kondisi pengujian. Hasil dari pengujian diperoleh bahwa minyak kemiri, minyak wijen dan minyak solar masing-masing 0,9 , dan 10 . Hasil dari pengujian bahwa minyak kemiri dan minyak wijen di bawah minyak solar. Hal tersebut menunjukkan bahwa pada suhu 0 dan 9 masih mampu mengalir.

Berdasarkan karakteristik bahan bakar, ketiga minyak tersebut memenuhi karakteristik sebagai minyak untuk digunakan pada proses pembakaran. Namun ketiganya perlu dilakukan pengujian pencampuran untuk mengetahui karakteristik setelah dilakukan pencampuran bahan bakar tersebut.

\section{B. Karakteristik Campuran Bahan Bakar}

Untuk melihat hasil karakteristik campuran bahan bakar setelah dicampur menjadi dua tahap yaitu dengan campuran minyak solar 90\% dan minyak kemiri 5\% serta minyak wijen 5\%. Tahap dua yaitu minyak solar $80 \%$ dan minyak kemiri $10 \%$ serta minyak wijen $10 \%$. Hasil yang diperoleh setelah pengujian dapat dilihat pada grafik berikut:

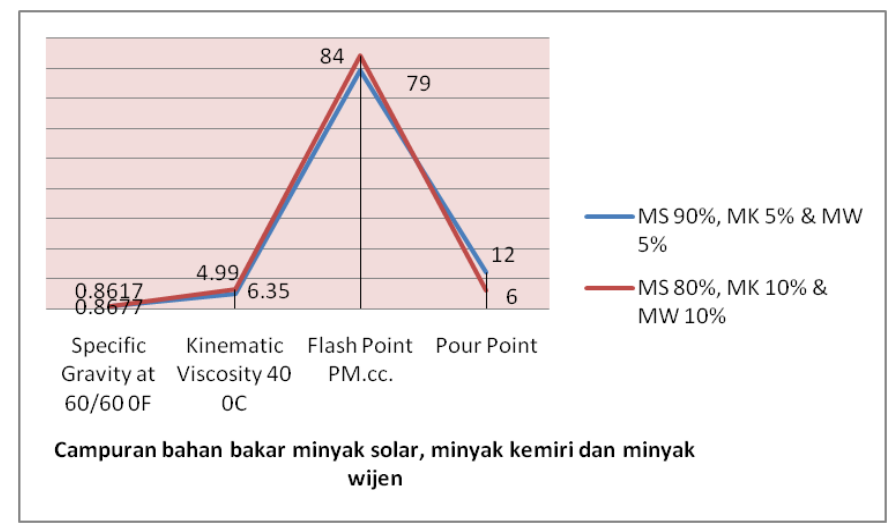

Gambar 2. Grafik Hasil Pencampuran Minyak Solar (MS),

Minyak Kemiri (MK), dan Minyak Wijen (MW)

Berdasarkan grafik di atas diperoleh bahwa campuran kedua dengan prosentase minyak solar $80 \%$, minyak kemiri $10 \%$ dan minyak wijen $10 \%$ menghasilkan minyak yang tidak mudah terkontaminasi dan lebih tingg yaitu 0.8677 , untuk viskositasnya lebih tinggi yaitu $6.354 \mathrm{~mm}^{2} / \mathrm{s}$, untuk titik nyala di atas standar yaitu $84,0{ }^{\circ} \mathrm{C}$ namun untuk pour point pada suhu $6{ }^{\circ} \mathrm{C}$ tetap mampu mengalirkan minyak. Dapat disimpulkan bahwa semakin banyak campuran prosentase minyak kemiri dan wijen menghasilkan karakteristik yang baik.

\section{Konsumsi Bahan Bakar terhadap Putaran Mesin}

Campuran konsumsi bahan bakar perlu dilakukan pengujian terhadap putaran mesin. Variasi putaran mesin yang diuji meliputi $1600 \mathrm{rpm}, 2000 \mathrm{rpm}$, dan $2300 \mathrm{rpm}$. Hasil dari pengujian tersebut, dapat diamati pada grafik berikut: 


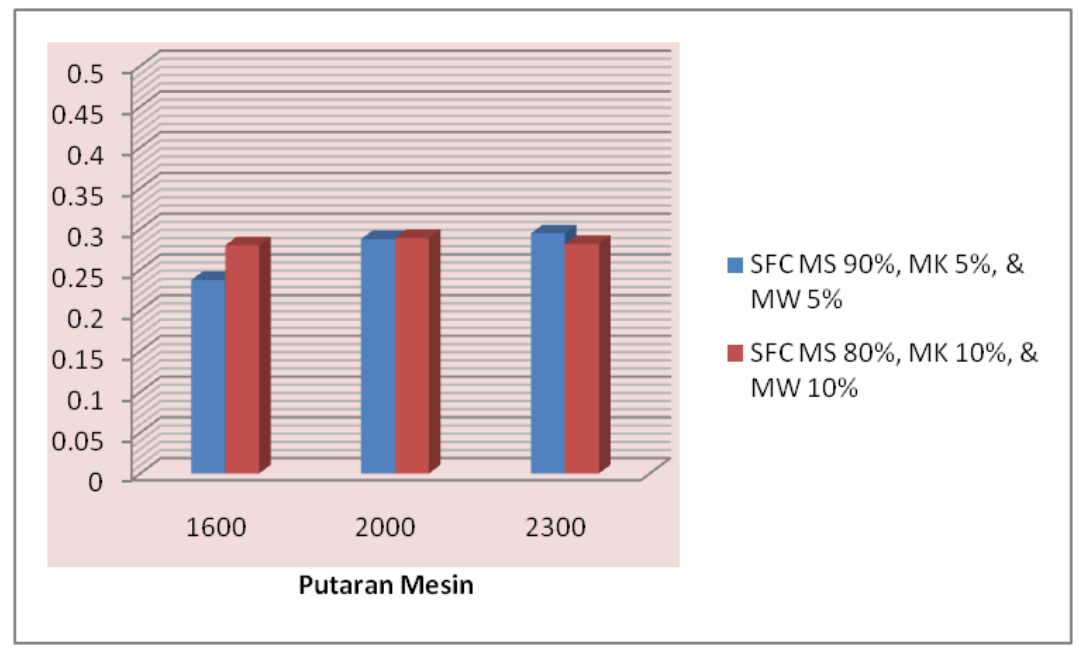

Gambar 3. Grafik Konsumsi Bahan Bakar Spesifik (SFC) terhadap Variasi Putaran Mesin.

Konsumsi bahan bakar spesifik (SFC) yang dihasilkan pada campuran bahan bakar minyak solar $80 \%$, minyak kemiri $10 \%$ dan minyak wijen $10 \%$, menghasilkan putaran mesin yang lebih stabil pada berbagai putaran yaitu $1600 \mathrm{rpm}, 2000 \mathrm{rpm}$, dan $2300 \mathrm{rpm}$ masing-masing SFC yang diperoleh sebagai berikut 0.279882, 0.288938, dan 0.281213. Sehingga dapat disimpulkan bahwa perbandingan campuran bahan bakar minyak solar dengan minyak kemiri dan minyak wijen yang lebih tinggi menghasilkan putaran mesin lebih stabil.

\section{KESIMPULAN}

Hasil penelitian di atas dapat disimpulkan bahwa:

1. Karakteristik bahan bakar minyak kemiri dan minyak wijen memenuhi karakteristik minyak yang dapat dicampurkan dengan bahan bakar solar untuk dijadikan bahan bakar alternative.

2. Karakteristik bahan bakar setelah dilakukan pencampuran dihasilkan bahwa pada pencampuran minyak solar $80 \%$ dengan minyak kemiri $10 \%$ dan minyak wijen 10\% menghasilkan karakteristik yang lebih baik. Sehingga diperlukan penelitian lanjutan dengan pencampuran yang lebih banyak.

3. Konsumsi bahan bakar menggunakan pencampuran dengan berbagai variasi putaran yang lebih stabil yaitu pada campuran minyak solar $80 \%$, minyak kemiri $10 \%$ dan minyak wijen $10 \%$. Semakin banyak campuran minyak kemiri dan minyak kemijen menghasilkan putaran yang lebih stabil.

\section{DAFTAR PUSTAKA}

Arlene, A., Suharto, I., dan Susatlo, B. 2009. Pengaruh Rasio Umpan Terhadap Pelarut dan Temperatur dalam Ekstraksi Minyak dari Biji Kemiri secara Batch terhadap Perolehan Minyak dari Biji Kemiri (Aleurites moluccana). Simposium Nasional RAPI VIII, 14129612.

Arlene, A., Suharto, I., dan Jessica, N. R. 2010. Pengaruh Temperatur dan Ukuran Biji terhadap Perolehan Minyak Kemiri pada Ekstraksi Biji Kemiri dengan Penekanan Mekanis. Prosiding Seminar Nasional Teknik Kimia “Kejuangan”. Pengembangan Teknologi Kimia untuk Pengolahan Sumber Daya Alam Indonesia. Yogyakarta, 26 Januari 2010. 
Direktorat Pendidikan Menengah Kejuruan. 2004. Modul Pemeliharaan/Servis Sistem Bahan Bakar Diesel. Yogyakarta. Fakultas Teknik. Universitas Negeri Yogyakarta.

Ketaren, S. 1986. Pengantar Teknologi Minyak dan lemak. Universitas Indonesia Press. Jakarta.

Kurdi, Ojo dan Arijanto. 2007. Aspek Torsi dan Daya Pada Mesin Sepeda Motor Empat Langkah Dengan Bahan Bakar Campuran Premium-Methanol.Rotasi. Volume 9. Nomor 2: 54-60.

Siswani, E. D., dan Kristianingrum, S. 2006. Penentuan Koefisien Perpindahan Massa pada Ekstraksi Minyak Kemiri (Lewat Model Matematika). J. Kim.No. 5.,40-49.

Sugiyono. 2013. Metode Penelitian Kombinasi (Mixed Methods). Bandung: Alfabeta.

Sukoco dan Zaenal Arifin. 2009. Pengendalian Polusi Kendaraan. Bandung: Alfabeta.

Sunanto, H. 2002. Budidaya Wijen Manfaat dan Aspek Ekonominya. Kanisius: Yogyakarta.

Supraptono. 2004. Bahan Bakar dan Pelumasan. Semarang. Jurusan Teknik Mesin. Fakultas Teknik. Universitas Negeri Semarang. 